\title{
Study of an ordinary home electrical consumption in order to make it more energy-efficient
}

\author{
António Manuel L. Quadros Flores \\ Energy Systems Group \\ Electrical Engineering Department \\ I.S.E.P. - Instituto Superior de Engenharia do Porto \\ Rua Dr. António Bernardino de Almeida, 431, 4200-072 Porto, Portugal \\ Telephone: +351-228 340 500, Fax: 228321159 \\ E-mail: aqf@isep.ipp.pt
}

\begin{abstract}
Taking care of our household energy can lower our annual power costs without making our home less comfortable, but making it more valuable.

The purpose of this paper is to show how to turn an ordinary home into a more energy-efficient one. To achieve that goal, we analysed all the electrical appliance consumptions in a real home and starting from there, we made tests and explained the results; in fact, it became more energy-efficient and consequently lowered the electricity bill. The goal of this paper is to make it clear that almost all homes have the potential to become more energy-efficient, not from a theoretical point of view, but from a practical one, starting from real data and ending in the annual savings in the electricity bills. In addition using electricity more efficiently we will be contributing to a more reliable electricity system and we will be doing our part to help protect the environment.
\end{abstract}

Key words: Electricity saving, energy-efficiency, environment, DSM

\section{Introduction}

It is common sense that electricity, when compared with other energy sources, is the cleanest and the most comfortable kind of energy. In fact when you plug something into the wall, it seems clean enough - you don't see or smell any pollution, as it happens with your car - but the pollution is there, it just takes place at the power plant [1]. So, saving electricity doesn't just save money, but it helps keep the air clean and the water as well.

\section{Demand Side Management}

Initially, "Demand Side Management”, (DSM), was used to describe the planning and implementation of the activities of the utilities, with the objective to influence the load demand shape [2]. DSM can now be seen as a new resource for successful electricity retail markets, for efficient system operation, and as way of reducing air pollution, as part of the global fight against climatic change, complying with the Kyoto Agreement of decreasing emissions of carbon dioxide. DSM policies should be able to consider the new scenario, and include advantages both to electricity retail companies and consumers [5]. Promoting energy saving and the production of "green energy" from the renewable energy sources, associated with power quality policies are efficient ways to achieve the same goals: reducing the planet pollution and the dependence on foreign fuel imports.

\section{Electricity use in an ordinary home}

The number and kind of appliances existing in the majority of family homes have many similarities: they all normally have one stove, one fridge, a few heaters, a few bulbs and so on.

The building size or type does not make a great difference in the appliance set normally found in these places. Maybe someone has one or more heaters, some more bulbs, but we can always estimate an average set adjusted to the normal family needs.

\section{A. Typical home appliance set}

The ordinary home, studied in this paper, is a place where there lives an average size family, and it is equipped with an appliance set fed by electricity. That includes the following appliances: one electrical stove, one electrical oven, one fridge, one freezer, one water heater, three heaters, one dishwasher machine, one washing machine, two TV sets (one big and another medium size), twelve 60W incandescent bulbs, four 40W incandescent bulbs, two $300 \mathrm{~W}$ incandescent bulbs, two 36W fluorescent lamps, one 1000W microwave, two computers, two printers, two $\mathrm{Hi}-\mathrm{Fi}$ sets, two video recorders, seven plug transformers (for charging mobile phones, toys, audio portable sets, wireless home phones, a video camera,...), ...

All these appliances stay normally connected or plugged to electricity. 


\section{B. Monitoring the electrical energy consumption}

This study involves the interpretation of all types of electricity use carried out on a ordinary day that we believe to be a typical day of a family home life. Although each day is a different day, we believe that almost every day there is a family routine caused by work, and home activities (cooking, cleaning, leisure and rest) that we can consider as defining a typical day. Electrical consumption monitoring charts were made as a starting point in order to have a clear view into the home load shape that resulted from the use of different appliances.

The following charts show some initial load monitoring on summer week days (before any change):

\section{1) Stove load}

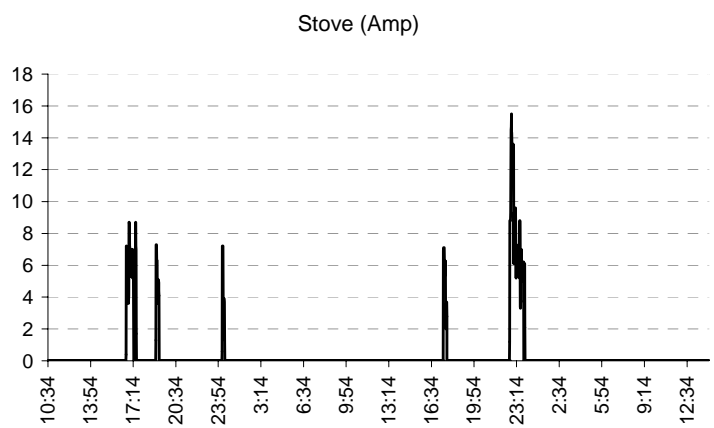

Figure 1- Stove load

As it can be seen on figure 1, cooking is carried out for short periods of time and it involves high loads.

\section{2) Water heater}

Water heater (Amp)

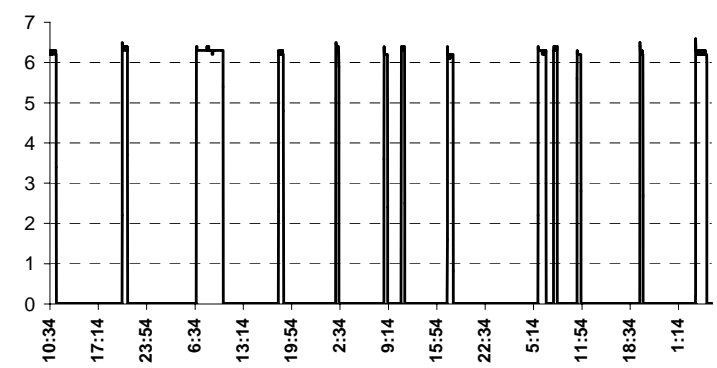

Figure 2- Water heater

The water heater chart shows the water heating process: it can be clearly seen that the energy consumption compensates the heat losses during the day and the heating energy to restore the tank water temperature after a shower.

\section{3) Light}

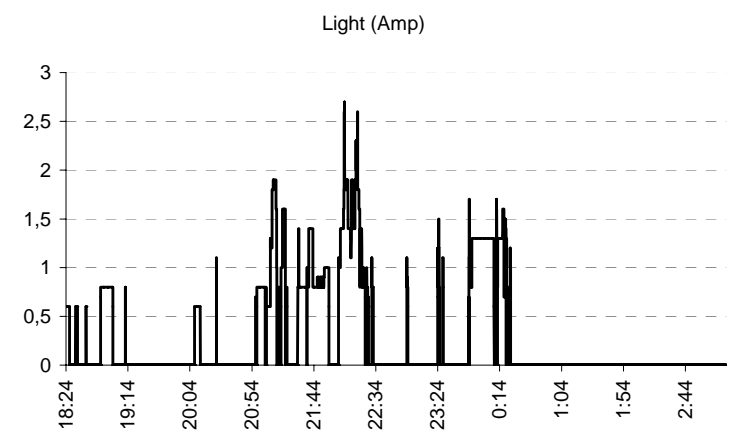

Figure 3- Light

Lighting does not involve big loads, but the chart shows that the lights stay on for long periods of time, which shows that this kind of load has some influence on the final consumption.

4) Mains

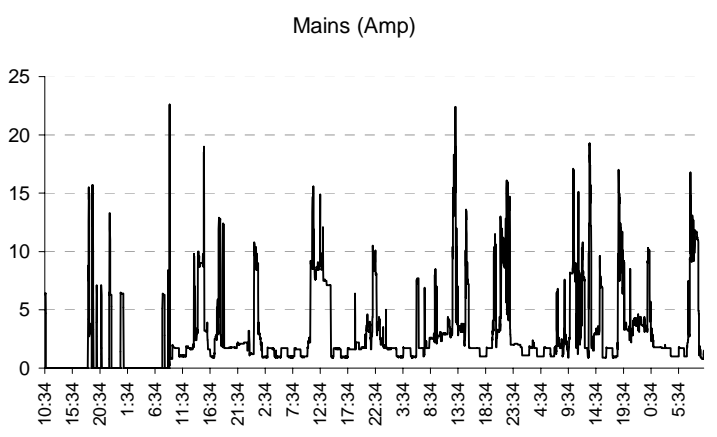

Figure 4- Mains

The mains chart shows the sum of all electrical loads: some sharp loads can be seen as well as a constant load of about 2 Amps. Now we need to have a closer look into each load individually.

\section{Procedures to improve energy efficiency at home}

The first step to take a whole-house energy efficiency approach is to find out which parts of the house use the most energy. A home energy audit will show those areas and suggest the most effective measures to cut the energy costs. It is worthwhile starting at the place where there are the greatest energy losses. Besides, we cannot forget how long it will take for an energy efficiency individual investment to pay for itself.

We included in this study the energy saving tests and tips in the areas of heating, hot water, appliances, cooking, lighting, fireplace, insulation and building.

The key to achieve these savings is a whole-house energy efficiency plan based on the following three steps [3]:
A) House's Thermal Envelope,
B) High-Efficiency Appliance,
C) Control over Household Energy Use 


\section{A. House's Thermal Envelope,}

The house's thermal envelope includes every item that separates the inside from the outside: the floor, walls, roof, windows and doors. These items can affect the house's heating and cooling loads.

A lot of energy can be wasted by letting the warm air leak into your home during the summer and out of your home during the winter.

When we think about warming up a room to a pleasant temperature we cannot forget that the heat we need to achieve that purpose depends mainly on the heat leakages of that room. Ideally a room without any losses would need only a small amount of heat, enough to warm up the enclosed air and the furniture and it would keep it until next summer comes, or being more utopian, it would keep the summer temperature throughout the winter!

In fact, space heating is intrinsically associated with heat losses. Then when we want to save energy we have to pay special attention to the thermal insulation around all the home envelope because it is there the place where we can really decrease the energy waste.

Checking insulation in your home is one of the fastest and most cost-efficient ways to use a whole-house approach to reduce energy waste. A good insulating system includes a combination of products and construction techniques that protect a home from outside temperatures, hot and cold, protect it against air leaks and control moisture.

A better insulation, besides saving energy, makes the place more comfortable, as it eliminates drafts and makes the temperature more stable.

By using infra-red cameras it can be seen, that heat leaks come mainly from windows, doors and chimneys. Taking care of the envelope insulation can be carried out in different ways:

- Increasing the thermal insulation of the floor, walls and ceiling by using adequate materials, normally projected in new constructions; also installing an extra insulation blanket, made of fibreglass or rock wool, in the attic, normally makes the place more comfortable, as it makes the room temperature more stable in winter, keeping the heat from the day through the night and, in the summer, delaying the indoor air from warming up so fast. In fact, one of the most cost-effective ways to make your home more comfortable year-round is to add insulation to your attic.

- Looking for air leaks it is normally very rewarding. As the figure 5 shows, about one-third of the infiltrated air is estimated to come through openings in the walls, ceilings, and floors.

- The toilet ventilation grate is an easy way for heat to escape. So keeping toilet doors closed can be a simple solution, mainly in windy days.

- Doors very often have a gap (about $1 \mathrm{~cm}$ ) underneath them and that results in heat leakage. Several insulation materials are available for this kind of gaps. Out doors must be carefully inspected for leakages.

- The fireplace, when not in use, is an easy way out, or in, allowing heat losses and also creating drafts. Keeping it closed when not in use is an easy solution.
- Installing a sealing window beside existing windows is very interesting as it decreases drafts, heat losses and also prevents noise from coming in. It is an advantage to use double glass and to pay attention to the sealing capability. When building a new home it is worthwhile thinking of installing energy-efficient windows.

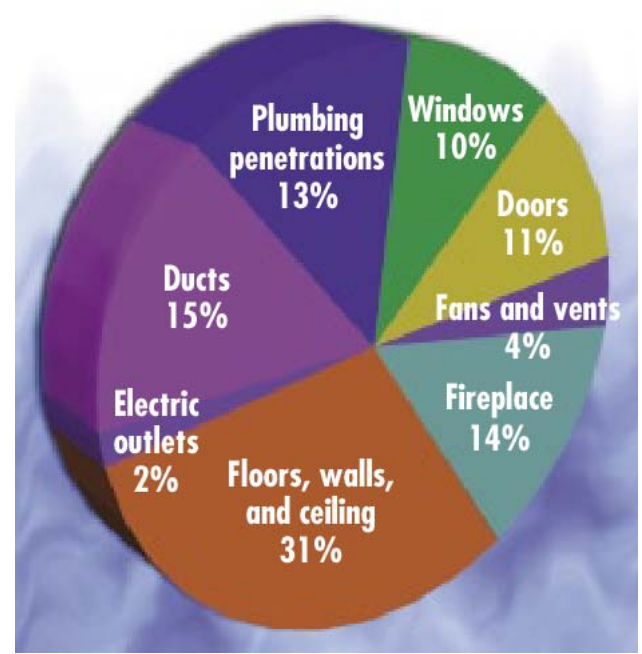

Figure 5-House air leaks [5]

- The floor, when made of wood, can contribute to thermal insulation and a feeling of comfort.

- At night all indoor doors should be kept closed, especially in windy days, in order to avoid drafts and loosing warmed air.

- The routine of opening blinds during winter sunny days can also help to get sun heat inside the house.

\section{B. High-Efficiency Appliance}

Home appliances have steadily become more energy efficient for the last decades. When buying new appliances we must consider the total cost that should include the running cost associated with the purchase price.

It is obvious that it is not worthwhile to replace all the appliances just to save energy, unless they become useless or obsolete. But when buying a new appliance it is important to keep in mind also the energy efficiency criteria. Doing so, after a while, our appliance set will become energy-efficient and, in the end, we are saving in the energy bills and we are contributing to a more efficient use of the electricity. Buying an high-efficiency appliance needs a bigger initial investment, but when added with a long run lower energy consumption it may be a better choice. Besides that, we should remember that choosing an high-efficiency appliance we are contributing to a better planet, decreasing emissions of carbon dioxide over the next few years

Using new lighting technologies can reduce energy use by $50 \%$ to $90 \%$. Advances in lighting controls offer further energy savings by reducing the brightness with dimmers or, with timers or photocells, the amount of time lights are on, but not being used. Replacing incandescent bulbs by low energy ones saves energy. It is more significant to make this replacement in high-use areas, such as rooms where light is on for longer periods of time, as for example the kitchen, 
the living room and outside lighting. Decorating with lighter colours will also help to save energy, as the light level to achieve the same comfort will be lower.

\section{Control Over Household Energy Use}

The way the household uses its electric appliances has a great influence in its energy efficiency. There are some energy-saving rules that can help consumers gain greater control over their electric bills.

\section{1) Fridges and freezers}

The fridge deserves some concern, as it is powered all year through. So a high efficient fridge can be an interesting advantage as it pays for itself. Keeping the refrigeration system clean and well ventilated decreases cooling time and saves energy; otherwise the cooling pump may be left running all the time.

Also it is a good practice to save energy opening the fridge or freezer doors the least number of times and by short periods of time.

\section{2) Room heaters}

Being energy-wise with the use of heat will help reduce winter energy bills. The heating solution can be one of the most potent sources of savings at home.

During cold weather, when the heaters must be on all the time, to save energy it is advisable to wear winter clothes at home so the thermostat setting temperature can be lowered. After a while, this becomes a habit and you still feel comfortable as your body easily adjusts to it and also it has the advantage of avoiding the temperature shock when going out. If possible, the heaters should be switched on at night using a clock switch set to turn on at $21 \mathrm{~h} 00$ and off at $7 \mathrm{~h} 00$ (2 hours before room use and 1 hour before room vacancy). Savings represent 14 hours of heat losses.

The seasonal effect on energy consumption must also be taken into account. For example, as far as the weather is concerned, it is obvious that if it is unusually cold or stays cold for a prolonged amount of time, the home heating bills can increase significantly. Keeping the thermostat at the lowest comfortable temperature (20 to 21 degrees) can save energy. Every degree above 21 costs an additional 7 to 10 percent [4]. During the winter months, it is a good practice to lower the thermostat at night or when leaving the house.

Heat pumps are the most efficient form of electric heating, providing three times more heating than the equivalent amount of energy they consume in electricity. They collect heat from outdoors and concentrate it for use inside. Heat pumps also can reverse its function working as air conditioner in summer. They can also cool the house by collecting the heat inside and effectively pumping it outside. A heat pump can trim the amount of electricity used for heating by as much as $30 \%$ to $40 \%$.

\section{3) Hot water}

The energy-efficiency of a water heater is related to its thermal insulation through which it loses heat.

It can be improved in a few ways: one is to increase the insulation with an extra blanket and the other one is to avoid drafts around it, keeping its room closed. As the hot water use represents an important part of the consumed energy, it is worthwhile to look at some simple procedures that can help you save energy. One of them it is to install a timer switch to turn on the water heater for about two hours before the expected needs; another it is program the timer switch to turn on the water heater during night hours if you have cheaper electricity at night. Lowering the thermostat of the hot water heater to $50^{\circ} \mathrm{C}$ it can bring about extra savings. Another way of saving hot water is to install low-flow aerating showerheads and faucets.

Tankless water heaters can save up to $30 \%$ compared with standard electric storage tank heaters, as they do not waste heat neither from the water heater losses nor along the pipes.

The modern faucets, that have a central lever to regulate the mix of hot and cold water, can be a source of wasting energy if not used conscientiously. When you open the tap lifting the lever and the lever is turned to the right, the water comes from the cold water pipe; when it is turned to the left it gives hot water and in between it comes more or less warm depending on the lever position. Normally when the lever is in the central position the tap mixes the same quantity of hot and cold water. This means that if the members of the family open the tap for just one, two or three litres of water and, by commodity they open the tap with the lever in the central position, they still get cold water, but it will be charged as using warm water.

It is well known that a shower uses less water than a bath and consequently it saves energy. Taking short showers, instead of baths, means savings. We can also add an extra saving if we turn off the tap while soaping the body. These little differences can become a habit and, at the end of the year, altogether they can be quite representative.

\section{4) Cooling}

Ventilation fans play a large role in providing moisture control and reducing summer cooling bills.

\section{5) Stove}

Good cooking habits can contribute to energy saving. When using a pan it is advisable to keep it with the lid on, to keep the heat inside and to make boiling easier; this way the heat setting can be set to a lower position. The regular use of pressure pans take less energy to cook, as it makes boiling possible at a lower temperature and it uses a lot less time to achieve the same cooking results.

\section{6) Washing Machine}

Making the washing machine run during the night saves money when it takes advantage of the cheaper electricity rate system. We can also save, using short and low temperature programs. Besides that, it is certainly a saving contribution to run the washing machine only with full loads. 


\section{7) Dish washers}

Air dry dishes, instead of using the dishwasher's drying cycle is a valuable saving contribution, as well as, washing only full loads of dishes.

\section{8) Microwave oven}

The regularly use of the microwave oven can save energy as it concentrates the heat in the food and does not waste heat to warm the surroundings.

\section{9) Exhaust fan}

While not currently mentioned we consider it a hungry heat eater. If it is regulated stronger than what is needed or if it is left working beyond stove use it is wasting energy as it is removing warm air from inside the home. Ideally, in construction, the kitchen air inlet should be built in order to lead outdoor fresh air straight to the fridge back in order to cool it (improving fridge efficiency) and use its heat to warm up the kitchen!

\section{0) Fireplace}

The fireplace is one of the most inefficient heat sources we can possibly use. It literally sends energy right up the chimney along with volumes of warm air. A roaring fire can exhaust a lot of air per hour to the outside, which must be replaced by cold air coming into the house from the outside. The home heating system must warm up this air, which is then exhausted through the chimney.

The fireplace can contribute to heat the place; however if it was not planned as a wholly integrated heat project, it can have the opposite effect of making the place cooler and of creating cold drafts. In fact, the fireplace needs an air inflow in order to give oxygen to the fire and let the smoke go up the chimney, helped by its high temperature. If a door or window is not open, while the fire is on, the place will get a lot of smoke which will make it very uncomfortable. To overcome all this, we can get fresh air from outside and warm it using the fireplace heat: we can make it pass through pipes around the fireplace and let it enter the room; without the need of opening any window it brings more oxygenated air to the room as well as heat, decreasing the need for heating energy. If you have a fireplace you don't use, it is advisable to close the flue, avoiding air drafts and loosing the warmed air.

\section{1) Lighting}

To turn off the lights when not needed does not cost anything, but it saves energy.

\section{2) Permanently connected loads}

Many loads are normally left permanently connected to electricity: phone chargers, TV sets, video recorders, entertainment systems, ... In fact they all have a small consumption in standby mode but, when we multiply this consumption by their number and by 8760 (hours of the year), it can become quite significant. Also it does not cost anything, but it saves energy to get used to turning off the TV set, when nobody is watching it; the same applies to other appliances as PC, monitors, etc.

\section{Electricity consumption measurements}

It could be interesting to know the electrical current wave forms that feed each appliance, but in fact, what really matters for our purpose, it is the individual consumption over a certain period of time that constitutes a contribution to the total consumption.

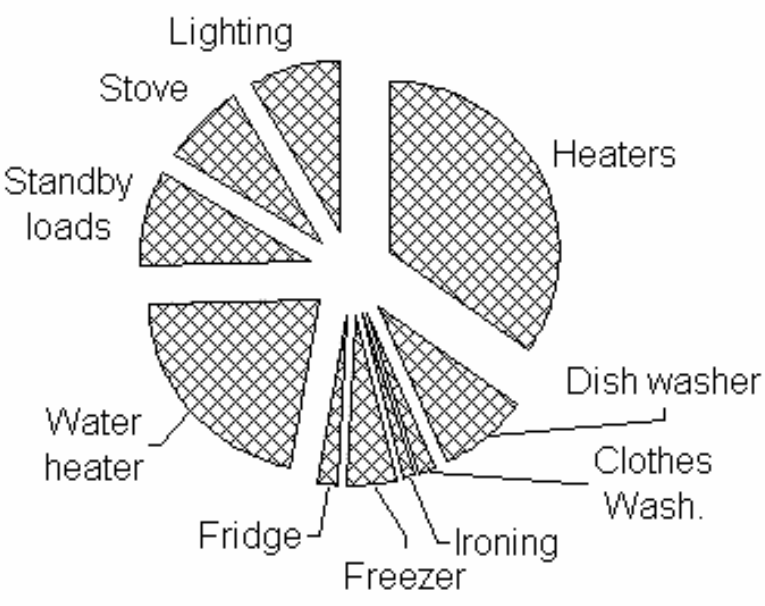

Figure 6- Electrical energy use

We measured the electrical energy use over a period of time during the month of December, and estimated the average energy consumption considering a heating load for only a third of the year. The pie graph (Figure 6) shows that heating is the main use of electricity: air heating, water heating, cooking and washing. In fact, concerning the washing machines, they mainly use energy to heat the water for washing. Standby loads also are meaningful, as well as lighting.

The electricity needed to satisfy each type of use depends on many factors. Concerning cooling and heating, the kind of climate where the place is located, can make the saving options very different. So, if someone can feel comfortable in a place during the day, with the heaters off, thanks to a well designed set of energy principles, that doesn't mean that the same is possible for a colder climate! Following the same idea, looking after an efficient sealing of the place envelope can have a major important influence in the saving capacity on a colder climate than in a temperate one. Despite this, we are going to present some electricity consumption measurements regarding different types of potential savings, making it clear that there may be still room for improving the house's thermal envelope, replacing an existing appliance by a high-efficiency one or adopting more efficient daily life routines. 


\begin{tabular}{|c|c|c|c|c|c|}
\hline & \multirow{3}{*}{$\begin{array}{l}\text { Read } \\
\text { KWh } \\
\text { Data }\end{array}$} & \multirow{3}{*}{\begin{tabular}{|c|} 
Average \\
Daily \\
KWh \\
average \\
\end{tabular}} & \multirow{3}{*}{$\begin{array}{c}\text { Average } \\
\text { Year } \\
\text { KWh } \\
\text { average }\end{array}$} & \multirow{3}{*}{$\begin{array}{c}\text { Bill } \\
\text { Year } \\
€ \\
0,098 € / K W h \\
\end{array}$} \\
\hline & & & & & \\
\hline & & & & & \\
\hline $\begin{array}{l}\text { Appliance } \\
\text { Heaters }\end{array}$ & $\frac{\text { Use }}{2 \text { heaters, } 10 \mathrm{~h}, \text { room } 21^{\circ} \mathrm{C} \text {, Nov-Feb }}$ & 12/heater/night & 24,00 & $2.920,00$ & 286,16 \\
\hline Dishwasher & 1 run, $40 \mathrm{mn}$ & 1,8/day & 2,00 & 730,00 & 71,54 \\
\hline Clothes Wash. & Warm washing, $30^{\circ} \mathrm{C}$ & $0,5 /$ day & 0,34 & 124,10 & 12,16 \\
\hline Ironing & daily average from 1 week data & 1,7/Week & 0,30 & 109,50 & 10,73 \\
\hline Freezer & $3^{\circ} \mathrm{C} 100 \mathrm{~L}$ & $1,1 /$ day & 1,10 & 401,50 & 39,35 \\
\hline Fridge & $-18^{\circ} \mathrm{C}, 100 \mathrm{~L}$ & $0,4 /$ day & 0,40 & 146,00 & 14,31 \\
\hline Water heater & $60^{\circ} \mathrm{C}, 80 \mathrm{~L}, 1.500 \mathrm{~W}$ & 35/week & 5,00 & $1.825,00$ & 178,85 \\
\hline Standby loads & 2 4h ON: 2TV,HiFi, PC,Phones,Alarm.. & 2,1/day & 2,10 & 766,50 & 75,12 \\
\hline Stove & average 3 meals a day & 1,8/day & 1,80 & 657,00 & 64,39 \\
\hline Lighting & $6 \times 60 \mathrm{~W}+1 \times 300 \mathrm{~W}, 3 \mathrm{~h}$ average & 2/day & 2,00 & 730,00 & 71,54 \\
\hline & Total & & 39,04 & $8.409,60$ & 824,14 \\
\hline
\end{tabular}

Table 1- Three electrical energy bills: starting point bill, with day and night rate advantage and with extra saving techniques.

We estimated (Table 1 ) the electrical energy consumption all over the year and its total cost on a basis of $0,098 €$ per kWh.

For the average energy day calculation we only considered two heaters kept on at night and for 4 months per year.

We tested the house for air tightness: on a windy day, we hold a lit incense stick next to the windows, doors, electrical boxes, plumbing fixtures, electrical outlets, ceiling fixtures, attic hatches, and other locations where there could be a possible air path to the outside. When the smoke stream travels horizontally, we may have located an air leak that may need sealing, or weather stripping. Concerning air leaks we found several weak points in the thermal envelope. The windows were not properly sealed in windy days. Around the window frames one could see dirty areas as the result of air leaking from outside (Figure 7).

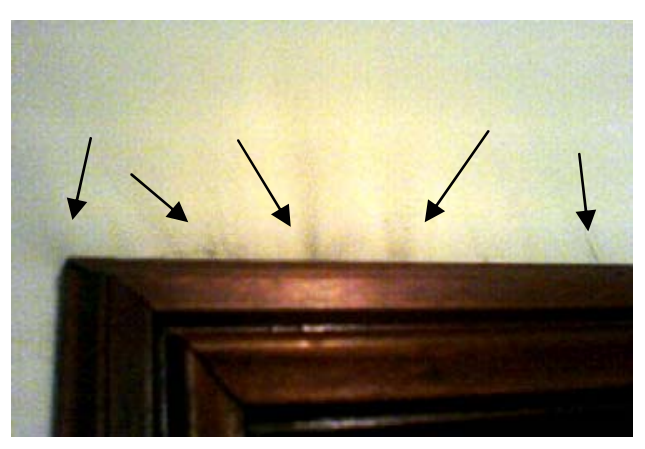

Figure 7- Air leaks

We also identified that the blind tape fittings were leaking air into the home. All these problems were solved with the installation of sealing windows that created a more uniform room temperature and increased comfort; installing new, high-performance windows improved home's energy performance. While it may take many years for new windows to pay off in energy savings, the benefits of added comfort and improved aesthetics and functionality may make the investment worth it; the energy saving could be seen straight away by looking at the thermostats of the heaters that, instead of being on most of the time, were only turned on for shorter periods of time. The investment went up to $1.000 €$ for the three room windows with double glass. The biggest advantage of this improvement was not so much the energy saving, but the room temperature stability that made it much more comfortable. Besides, it decreased noise from outside. The measurements showed that the energy spent of $12 \mathrm{KWh}$ per room per day lowered to $8 \mathrm{KWh}$. This improvement represents an energy saving of $30 \%$.

The fireplace, when not in use, originated drafts losing heat like an open window 24 hours a day. The living room temperature was cold despite the fact that a powerful heater was on all the time. To solve this problem we installed in the fireplace chimney a register manually operated. These leakages were not quantified in terms of wasted energy as they depend on the wind conditions.

We replaced the regular light bulbs with low energy ones, getting extra savings of up to $90 \%$ in lighting energy.

Keeping the appliances off, instead of standby mode, it can add savings up to $700 \mathrm{KWh}$ per year (0,5A x $230 \mathrm{~V}$ x $24 \mathrm{~h} \times$ 365days $=1007 \mathrm{kWh}$ ). 


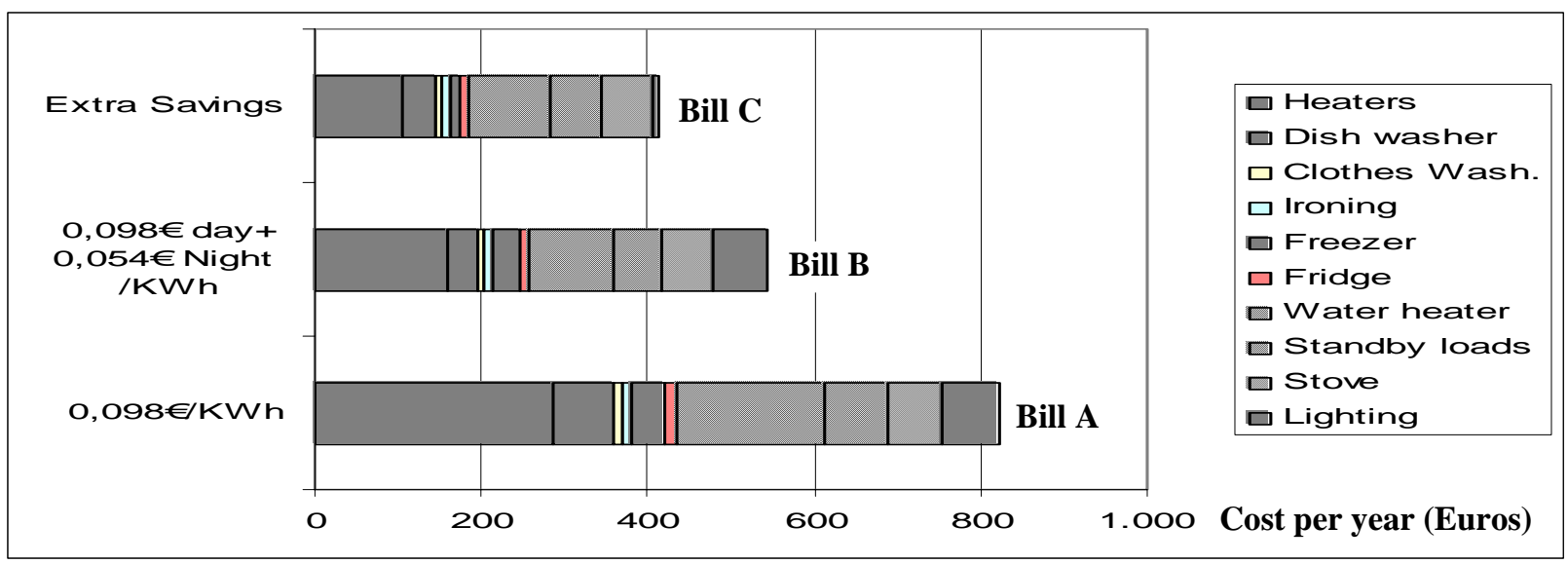

Figure 8- Three electrical energy bills: starting point bill, with day and night rate advantage and with extra saving techniques.

There are some loads that must be on all the time as the burglar alarm, electrical alarm clock's, etc. The TV sets, the entertainment system and the charger transformers standby mode can use $300 \mathrm{kWh}$ per year; the computer standby mode can also take $300 \mathrm{KWh}$ per year. We cannot forget that these tiny loads, altogether, increase the energy bill.

Concerning the use of the dishwasher and washing machine, taking advantage of the lower night energy rates we also can save in the energy bill. So running the dishwasher and the washing machine at night it results in annual savings of $38 €$.

\section{Real electricity saving}

First we measured all the home loads getting to the estimated average bill A (Table 2).

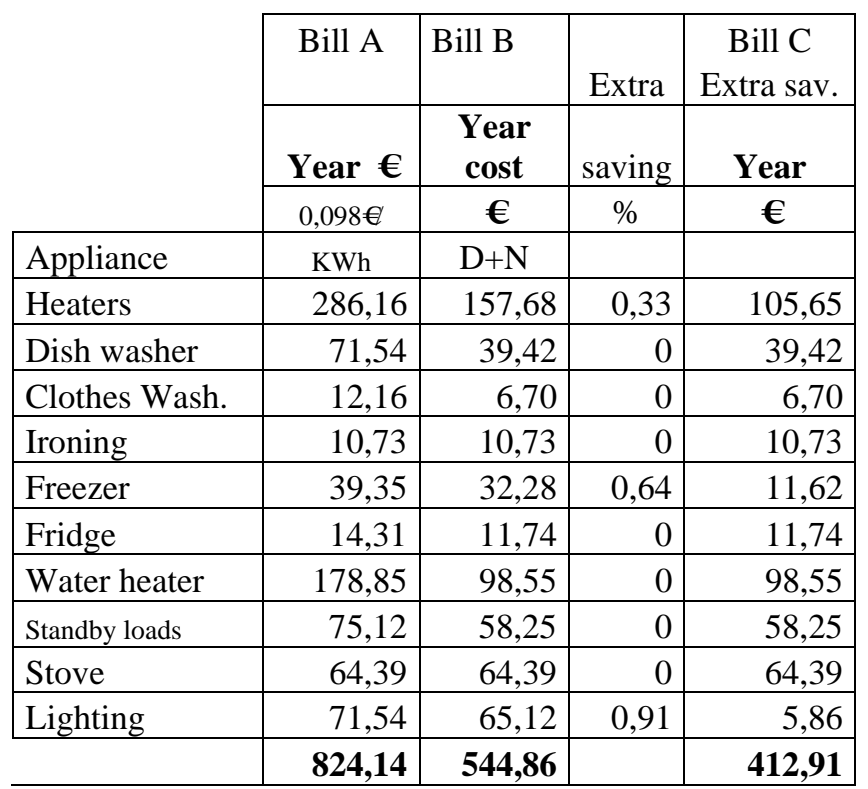

Table 2- The energy bills showing the electricity saving results.
The total heating loads (heaters, water heater, ironing and cooking) uses $65 \%$ of the total day energy, what makes us think of a way to improve its use. With a timer we can programme to turn on the water heater and the washing machines during the night. As a first approach to saving, we can take the advantage of the day and night energy rates making a saving of $30 \%$ shown by the bill B (Table 2 ).

We can still get extra saving by looking how to improve the use of energy regarding the bigger pie slices shown in figure 6. We tried extra savings using the following techniques: controlling the room heat leaks with sealing windows installed in the bedrooms (30\% energy saving), buying a new freezer with better energy-efficiency (30\% energy saving), and replacing the light bulbs by low energy compact fluorescent lights (30\% energy saving). With all these improvements we achieved about $50 \%$ reduction on our electricity bill C (Figure 8), compared with bill A! We could also decrease some standby loads (as the TV sets and $\mathrm{PC}$ ) by disconnecting them using extension switches.

By combining proper equipment maintenance and upgrades with appropriate insulation, air sealing, and thermostat settings, we can cut the energy bills and the pollution output in half.

\section{Conclusion}

This paper shows how easy it can be to reduce energy use at home. Although limited to a specific home and family style, it can be applied to a large amount of dwellings and has the advantage of being a simple proof showing that there is always room to make the house more energy-efficient. Very often, with just a few small changes in the household routines one can also add up over the year to good savings on the utility bills. We explained that there are simple, inexpensive steps families can take to reduce their heating and cooling costs.

Energy-efficiency awareness, as "Demand Side Management", can be an advantage to electricity retail companies, to consumers and to the environment. 


\section{References}

[1] Bluejay, Michael, "Saving Electricity", http://michaelbluejay.com/electricity, U.S.A. 2005

[2] Clark W. Gellings, John H. Chamberlin, "Demand Side Management - Concepts and Methods", The Fairmont Press/Presentice Hall, USA 1993.

[3] Edison Electric Institute, "The Added Value of an Energy Efficient Home”, http://www.eei.org, U.S.A.

[4] Progress Energy, "Energy Saving Tools", http://www.progress-energy.com, New York, U.S.A.

[5] V. Figueiredo, D. Rodrigues, Z. Vale,"Simulating DSM Impact in the New Liberalized Electricity Market", Polytechnic Institute of Porto, School of Engineering, Porto, Portugal 2005

[6] U. S. Department of Energy, "Energy Savers, Tips on saving energy \& money at home", www.eere.energy.gov/consumers/tips/, U.S.A. 2005 